\title{
EFEITO DA INOCULAÇÃO DO FITOPLASMA DO ENFEZAMENTO SOBRE O DESENVOLVIMENTO E PRODUÇÃO DE HÍBRIDOS DE MILHO*
}

\author{
CLÁUDiA M. TOFFANELLI \& IVAN P. BEDENDO**
}

\author{
Departamento de Entomologia Fitopatologia e Zoologia Agrícola, ESALQ-USP, Cx. Postal 9, CEP 13418-900, \\ Piracicaba, SP, e-mail: ipbedend@carpa.ciagri.usp.br
}

(Aceito para publicação em 25/07/2001)

Autor para correspondência : Ivan P. Bedendo

TOFFANELLI, C.M. \& BEDENDO, I.P. Efeito da inoculação do fitoplasma do enfezamento sobre o desenvolvimento e produção de híbridos de milho. Fitopatologia Brasileira 26:756-760. 2001.

\section{RESUMO}

O efeito isolado do fitoplasma sobre o desenvolvimento e a produção de dez híbridos de milho (Zea mays) foi avaliado em condições controladas. Plantas com dez dias de idade foram experimentalmente inoculadas através de dez insetos infetivos de Dalbulus maidis por planta. Plantas infetadas foram comparadas com plantas livres de fitoplasma quanto à sintomatologia e à alteração de alguns componentes de produção. As plantas infetadas exibiram avermelhamento foliar, proliferação de espigas anormais e enfezamento em maior ou menor grau, em função de cada híbrido. Para os híbridos mais suscetíveis, além da grande proporção de grãos miúdos, foram constatadas redução de até $35 \%$ na altura de plantas, $98 \%$ na produção de grãos, $72 \%$ no tamanho de espigas, $50 \%$ no número de fileiras/espiga, $98 \%$ no número de grãos/espiga e $18 \%$ na germinação de sementes.

Palavras-chave adicionais: molicutes, Zea mays, avermelhamento do milho.

\section{ABSTRACT \\ Effect of the inoculation of the maize bushy stunt phytoplasma on the development and kernel yield of corn hybrids}

The effect of the phytoplasma on the development and yield of ten corn (Zea mays) hybrids was evaluated. Ten-dayold plants were experimentally inoculated using ten infective insects of Dalbulus maidis/plant. Infected and healthy plants were compared regarding symptoms and yield components. Infected plants exhibited predominantly reddening of leaves, ear proliferation and stunting of different intensities. Reduction in plant height and kernel yield varied among hybrids. Reductions as high as 35\% in plant height, $98 \%$ in kernel yield and number of grains/ear, $72 \%$ in ear size, $50 \%$ in number of lines/ear, and $18 \%$ in seed germination occurred in the most susceptible hybrids.

\section{INTRODUÇÃO}

Os enfezamentos vermelho e pálido causados, respectivamente, por fitoplasma e espiroplasma, são doenças de relevante importância econômica para a cultura do milho (Zea mays L.). A forma vermelha tem sido predominante no campo e tem ocorrido com alta incidência em diversas regiões de diferentes estados brasileiros (Silva 1991; Folegatti et al., 1997; Dudienas et al., 1997; Oliveira et al., 1998). A alta incidência tem resultado em sérios danos à produção, provocando redução no rendimento da cultura e na qualidade dos grãos (Oliveira et al., 1998; Massola et al., 1999a). Resultados semelhantes têm sido relatados em outros países (Hruska et al., 1996; Scott et al., 1977). A disseminação do fitoplasma é feita através de cigarrinhas, destacando-se como

\footnotetext{
* Parte da dissertação de doutorado do primeiro autor. ESALQ, Piracicaba.

***Bolsista do CNPq
}

principal vetora a espécie Dalbulus maidis De long \& Wolcott (Nault, 1980). Nas condições brasileiras, o pico populacional do vetor ocorre nos meses de março e abril, favorecendo a disseminação do patógeno e a elevada freqüência da doença na chamada cultura de safrinha (Waquil et al.,1997; Oliveira et al., 1998).

A incidência dos enfezamentos e o comprometimento da produção estão relacionados à suscetibilidade do híbrido, à população de vetores e ao estádio de desenvolvimento das plantas na época de infecção (Bedendo, 1999; Massola et al., 1999a; Scott et al., 1977; Hruska \& Peralta, 1997). Avaliações sobre o comportamento de variedades e híbridos de milho têm revelado variações enormes quanto ao grau de resistência dos materiais testados, havendo predominância dos genótipos altamente suscetíveis (Borges, 1997; Dudienas et al., 1997; Oliveira et al., 1998).

As avaliações feitas no campo baseiam-se nos registros de rendimento da cultura e na observação de sintomas. Além 
Efeito da inoculação do fitoplasma do enfezamento sobre o desenvolvimento...

disso, têm levado em consideração o complexo formado pela associação entre fitoplasma e espiroplasma, ambos transmitidos pelo mesmo vetor. Assim, não se tem diferenciado o efeito isolado de um e de outro patógeno. Um dos raros trabalhos em que se estudou o efeito isolado destes patógenos foi conduzido por Massola et al. (1999b), os quais avaliaram o efeito da época de inoculação de espiroplasma sobre os diversos componentes de produção de dois híbridos suscetíveis. No entanto, não existem informações sobre o efeito isolado do fitoplasma do milho sobre o desenvolvimento de sintomas e, principalmente, sobre os componentes de produção. Assim, o presente trabalho teve por objetivos caracterizar os tipos e a severidade de sintomas, bem como avaliar os componentes de produção em híbridos de milho, com diferentes níveis de resistência, inoculados com o fitoplasma do enfezamento vermelho.

\section{MATERIAL E MÉTODOS}

O ensaio foi conduzido em telado anti-afídeo, usandose sementes dos híbridos comerciais XLX 520, Z 8452, CO 909, P 3063, P 3081, AG 3010, FT 9006, FT 9043, DO 02 e D 766. Estes híbridos apresentaram níveis variados de resistência, quando avaliados sob condições naturais de infecção.

Sementes pré-germinadas foram plantadas em copos plásticos de $250 \mathrm{ml}$, contendo como substrato uma mistura esterilizada de solo, areia e matéria orgânica, na proporção $3: 1: 1$. Plantas com dez dias de idade foram inoculadas com dez insetos infetivos/planta, os quais permaneceram confinados por quatro dias, por meio de gaiolas representadas por garrafas plásticas. Após o período de inoculação, as gaiolas foram removidas e os insetos eliminados pela pulverização do inseticida imidaclopride $(2 \mathrm{~g} / \mathrm{l})$. Em seguida, cada planta foi transferida para um saco plástico de 51 , contendo o mesmo tipo de substrato usado nos copos. Dois tipos de testemunhas foram utilizadas: plantas infestadas com dez insetos sadios/ planta e plantas não submetidas à alimentação de insetos.

A população infetiva de $D$. maidis foi obtida conforme a técnica descrita por Nault (1980). Ninfas de $2^{\circ}$ e $3^{\circ}$ ínstares, criadas em plantas de milho sadias, foram confinadas no cartucho de plantas fontes de fitoplasma, através de um saco de tecido (voal). Nestas plantas, pertencentes ao híbrido XL 333 , permaneceram durante quatro dias e, em seguida, foram transferidas para plantas sadias, nas quais foram mantidas por 21 dias, correspondentes ao período de latência. A população sadia foi obtida a partir da postura de insetos livres de fitoplasma em plantas mantidas em caixas teladas. A criação massal do inseto foi iniciada a partir da eclosão das ninfas.

Os sintomas foram registrados através de observações semanais. No estádio de grão leitoso, o número de espigas por planta e a altura das plantas foram registrados. Após a colheita, foram determinados o comprimento, o número de fileiras de grãos e o número de grãos para cada espiga. A produção de cada planta foi medida com base no peso de grãos com teor de umidade de $12 \%$. Teste de retenção em peneiras foi realizado visando avaliar o tamanho dos grãos, utilizando-se um conjunto de oito peneiras de malhas circulares, cujos diâmetros variaram de 7,14 a $9,52 \mathrm{~mm}$. A germinação das sementes foi determinada pelo teste padrão de germinação, de acordo com as regras para análise de sementes (Brasil, 1992).

As técnicas de PCR (Polymerase Chain Reaction) e ELISA (Enzyme-linked immunoabsorbent assay) foram aplicadas em plantas sintomáticas amostradas dentre aquelas inoculadas e nas plantas fontes, com a finalidade de se demonstrar a presença de fitoplasma e ausência de espiroplasma, respectivamente. $\mathrm{O}$ isolamento de DNA das folha e a PCR foram processados segundo o método de Lee $e t$ al. (1993), sendo utilizados os pares de iniciadores $\mathrm{mF} 2 / \mathrm{R} 1$ (5'-catgcaagtcgaacgga-3'/5'cttaaccccaatcatcgac-3') e F2n/R2 (5' -gaaacgactgctaagactgg-3'/5' -tgacgggcggtgtgtacaaaccccg3'). No PTA-ELISA, antissoro policlonal específico para o espiroplasma do milho foi utilizado (Mowat \& Dawson, 1987).

$\mathrm{O}$ delineamento experimental foi do tipo inteiramente casualizado (fatorial $10 \times 3$ ), com três repetições, sendo cada parcela representada por uma planta. A análise foi realizada por meio do programa "SAS for Windows" (SAS Institute, Cary, NC). Os dados originais foram utilizados para altura de plantas, comprimento de espigas e produção de grãos, sendo os dados transformados em $\sqrt{\mathrm{x}+1}$ para número de espigas, de fileiras e de grãos. $O$ teste Tukey foi aplicado ao nível de $5 \%$ de probabilidade.

\section{RESULTADOS E DISCUSSÃO}

Sintomas de clorose marginal e apical, seguida de avermelhamento, foram observados nas folhas, em oito dos dez híbridos avaliados, a partir dos 30 dias após a inoculação. Plantas testemunha não apresentaram sintomas. Os híbridos FT 9006, C 909, P 3063, P 3081, AG 3010, FT 9043, XLX 520 e Z 8452 apresentaram reações semelhantes quanto ao avermelhamento, havendo, no entanto, variação na intensidade da cor vermelha. Este sintoma se manifestou inicialmente nas folhas mais velhas, e, em seguida, nas folhas mais jovens, à medida em que eram emitidas pelas plantas. A presença de enfezamento, redução de altura de plantas, proliferação de espigas anormais, brotações axilares, perfilhos e folhas retorcidas foi observada, de maneira geral, nos híbridos, durante o desenvolvimento das plantas inoculadas. Os híbridos D 766 e DO 02 apresentaram reação diversa dos demais híbridos, não desenvolvendo avermelhamento nas folhas, mas áreas de coloração parda. Sintomas menos severos de enfezamento foram observados em plantas pertencentes aos híbridos Z 8452, FT 9006, FT 9043, P 3063 e D 766.

A predominância do avermelhamento associado ao fitoplasma está relatada em outros artigos, confirmando os resultados obtidos neste trabalho (Bedendo, 1999; Nault, 1980; Oliveira et al., 1998;). Vale ressaltar, entretanto, que embora o avermelhamento predomine em plantas infetadas por fitoplasma, o mesmo pode estar associado também a 
espiroplasma, não sendo, portanto, um sintoma típico para a diagnose de enfezamento vermelho (Bajet \& Renfro, 1989; Massola et al., 1999a; Nault, 1980). O aparecimento de áreas pardas, em lugar do avermelhamento, não se constituiu em novidade, pois de acordo com Nault (1980), uma variação de sintomas pode ocorrer em função do genótipo e do ambiente. Os demais sintomas observados nas plantas inoculadas, como redução de altura, brotações e proliferação de espigas, também podem ser causados tanto por fitoplasma como por espiroplasma e podem se manifestar com maior ou menor intensidade, dependendo de fatores diversos como suscetibilidade e estádio fenológico do hospedeiro, condições de ambiente e população de vetor, entre outros (Bedendo, 1997; Bedendo, 1999; Massola et al., 1999b; Nault, 1980; Oliveira et al., 1998). Estes resultados reforçam a sugestão de Davis (1995) de que a diagnose com base nos sintomas deve ser confirmada através da detecção destes molicutes no tecido de plantas sintomáticas.

A altura das plantas inoculadas foi significativamente menor nos híbridos C 909, P 3081, DO 02, AG 3010 e XLX 520 , sendo que as plantas afetadas apresentaram uma redução média de $35 \%$, quando comparadas com as plantas testemunhas. Para os demais híbridos, houve uma tendência das plantas inoculadas apresentarem redução de altura, em relação às plantas normais.

A redução de altura tem sido freqüentemente descrita para plantas infetadas por fitoplasma (Bedendo, 1999; Hruska \& Peralta, 1997; Shurtleff, 1986). Nas condições do ensaio, para alguns híbridos, foi bastante visível a diferença entre plantas inoculadas e não inoculadas. No entanto, nestas mesmas condições, não se constatou redução na altura de plantas inoculadas para determinados híbridos, evidenciando a ocorrência de variação entre híbridos quanto à expressão deste sintoma. Este mesmo tipo de observação tem sido relatada por diversos pesquisadores, tanto em materiais colocados no campo, como naqueles estudados sob condições controladas (Nault, 1980; Hruska \& Peralta, 1997; Oliveira et al., 1998; Massola et al., 1999a). Assim, a presença de fitoplasma pode implicar ou não em redução da altura da planta, dependendo do genótipo do material de milho.

A produção de grãos também foi reduzida de maneira significativa em quatro dos 10 híbridos avaliados. Os valores médios de redução foram de 70, 73, 79, e 98\% para os híbridos P 3081, P 3063, C 909 e XLX 520, respectivamente, quando as plantas inoculadas foram comparadas com as plantas testemunhas. Um efeito negativo do patógeno sobre o rendimento de grãos foi constatado para os demais híbridos, embora esta diferença não tenha sido detectada pela análise estatística. Não foi constatada diferença significativa entre a produção de plantas testemunhas infestadas por insetos livres de fitoplasma e de plantas não submetidas aos insetos.

A importância da doença para a cultura do milho está justamente relacionada com os danos relevantes decorrentes da infecção pelo patógeno. Perdas na produção têm sido frequentemente constatadas em áreas cultivadas com milho, atingido normalmente valores médios acima de $50 \%$, porém a produção pode ser nula em função do genótipo da planta, da época de infecção e da população do vetor (Hruska \& Peralta, 1997; Oliveira et al., 1998; Scott et al, 1977). Portanto, os resultados no presente trabalho demonstraram que a presença de fitoplasma pode levar a um sério comprometimento da produção.

O número de espigas anormais, caracterizadas por apresentarem tamanho pequeno e grãos miúdos, foi significativamente maior nas plantas inoculadas. Assim, os híbridos C 909, AG 3010, FT 9006, FT 9043, P 3063, D 766 apresentaram em média, 3,6; 3,8; 4,2; 5,0; 5,2 e 5,3 espigas/ planta, enquanto os híbridos P 3081, DO 02 e Z 8452 produziram, em média, duas espigas/planta. A maioria das plantas pertencentes ao híbrido XLX 520 não chegou a produzir espigas. Plantas testemunhas, independentemente de terem ou não sido submetidas à população de insetos livres de fitoplasma, produziram espigas normalmente.

A proliferação de espigas mal formadas é uma característica comum em plantas portadoras de fitoplasma (Bedendo, 1999; Nault, 1980; Oliveira et al., 1998; Scott et al., 1977). Assim, a ocorrência desta anomalia em praticamente todos os híbridos inoculados era esperada, inclusive a proliferação mais acentuada em alguns dos híbridos. O fato do híbrido XLX520 não ter produzido espiga pode ser uma evidência da alta suscetibilidade deste material. Juntamente com o avermelhamento, a formação de espigas extranumerárias é um sintoma bastante evidente, sendo útil na diagnose da doença. No entanto, este sintoma também pode ser causado por espiroplasma (Massola et al., 1999a; Bedendo, 1997; Nault, 1980) não servindo como parâmetro único para identificação de doença associada ao fitoplasma.

O tamanho das espigas produzidas por plantas inoculadas foi significativamente menor do que o das produzidas pelas plantas testemunhas, para todos os híbridos avaliados. A redução do tamanho variou de 52,5 a 72,5\%, ou seja, as espigas anormais corresponderam à metade ou até $1 /$ 4 do tamanho de uma espiga normal. Plantas não inoculadas apresentaram espigas de tamanho normal, variando de 12 a $16 \mathrm{~cm}$, de acordo com o híbrido, nas condições do ensaio. A redução no tamanho das espigas tem sido relatada por outros autores através de observações visuais (Hruska \& Peralta, 1997; Oliveira et al., 1998), sem, no entanto, ter sido dimensionada. Apesar da redução no tamanho das espigas ter sido constatada, indistintamente, para todos os híbridos inoculados, o grau de redução foi mais acentuado em alguns híbridos que em outros.

O número de fileiras de grãos/espiga foi variável entre os híbridos inoculados. Assim, uma redução média de 15\% foi constatada para os híbridos P 3081, DO 02, AG 3010, Z 8452 e C 909. Espigas dos híbridos D 766, FT 9006 e FT 9043 formaram somente $2 / 3$ do número total de fileiras presentes nas espigas normais, as quais produziram de dez12 fileiras. As reduções mais severas foram observadas nos híbridos P 3063 e XLX 520, os quais apresentaram 50\% e $20 \%$ do número de fileiras presentes nas espigas normais, respectivamente. Quanto ao número de grãos/espiga, houve 
Efeito da inoculação do fitoplasma do enfezamento sobre o desenvolvimento...

variação dentro de uma faixa ampla, em função do híbrido e da inoculação das plantas. Os valores extremos foram encontrados para os híbridos FT9006 e XLX520 com reduções significativas variando de 5 e $98 \%$, respectivamente. Reduções em torno de $50 \%$ foram constatadas para os híbridos Z 8452 , P 3063 e DO 02, quando plantas inoculadas e testemunhas foram comparadas. Apesar da suposição inicial de que quanto menor a espiga menor o número de fileiras e o número de grãos/espiga, não foi possível estabelecer uma correlação entre estes três parâmetros. Assim, híbridos que apresentaram espigas de tamanho semelhante, mostraram disparidade relevante quanto aos dois outros parâmetros avaliados. Por outro lado, híbridos que produziram espigas de tamanho diferenciado, mostraram semelhança para fileiras e/ou número de grãos/espiga.

O teste de retenção em peneiras evidenciou uma predominância absoluta de grãos miúdos originários de plantas inoculadas. Considerando-se todos os híbridos, $92 \%$ dos grãos produzidos por plantas infetadas passaram ou ficaram retidos na peneira de menor malha $(7,14 \mathrm{~mm})$. Por outro lado, ainda considerando uma média de todos os híbridos, somente $14 \%$ dos grãos provenientes de plantas normais foram retidos ou passaram por esta peneira. A germinação de sementes, de modo geral, foi afetada negativamente pela presença de fitoplasma na planta. Reduções de $18,16,14$ e $12 \%$ foram registradas para os híbridos P 3063, C 909, XLX 520 e AG 3010, respectivamente. Deve ser ressaltado, no entanto, que para os demais híbridos, a porcentagem de germinação foi semelhante entre sementes produzidas por plantas inoculadas e plantas livres de fitoplasma.

A presença de fitoplasma nas plantas fontes e naquelas sintomáticas que foram amostradas durante a condução do ensaio foi confirmada por PCR. O teste de ELISA demonstrou a ausência de espiroplasma nestas mesmas plantas.

A incidência dos enfezamentos nas culturas de milho instaladas no território brasileiro tem sido alta, resultando em perdas relevantes. A grande maioria dos híbridos avaliados tem se mostrado suscetível. No campo, fitoplasma e espiroplasma ocorrem formando um complexo, cujos sintomas e efeitos isolados de cada patógeno são difíceis de serem separados. Utilizando dois híbridos, Massola et al. (1999b) demonstraram os danos causados pelo espiroplasma atuando isoladamente. No presente trabalho ficou evidenciado o efeito isolado do fitoplasma, em relação à sintomatologia e sobre os diferentes componentes da produção. Assim, a soma de esforços vem contribuindo para um maior conhecimento sobre estas doenças, com o objetivo de mostrar sua real importância para a cultura do milho e de fornecer subsídios para o seu controle.

\section{AGRADECIMENTOS}

Os autores expressam seus agradecimentos aos professores Décio Barbin e Sônia Piedade do Setor de Matemática e Estatística da ESALQ/USP pelas sugestões. Ao professor João R. S. Lopes e Charles M. de Oliveira do Laboratório de Insetos Vetores do Setor de Entomologia da ESALQ/USP pelo apoio na criação dos vetores e fornecimento de plantas fontes de fitoplasma.

\section{REFERÊNCIAS BIBLIOGRÁFICAS}

BAJET, N.B.\& RENFRO, B.L. Occurrence of corn stunt spiroplasma at different elevations in Mexico. Plant Disease 73:926-930. 1989.

BEDENDO, I.P. Enfezamento vermelho e enfezamento pálido do milho associados a fitoplasma e espiroplasma: sintomatologia, etiologia e técnicas para detecção e identificação destes agentes. Summa Phytopathologica 25:190-196. 1999.

BEDENDO, I.P. Espiroplasmas patogênicos a plantas. Revisão Anual de Patologia de Plantas 5:99-131. 1997.

BORGES, R.T.P.B. Método de seleção em milho para resistência ao vírus da risca, fitoplasma e espiroplasma. (Tese de Doutorado). Piracicaba. Escola Superior de Agricultura Luiz de Queiroz-ESALQ/USP. 1997.

BRASIL. Ministério da Agricultura e Reforma Agrária. Regras para Análise de Sementes. Brasília, DF. 1992.

DAVIS, R.E. Fitoplasmas: fitopatógenos procarióticos sem parede celular, habitantes de floema e transmitidos por artrópodes. Revisão Anual de Patologia de Plantas 3:127. 1995.

DUDIENAS, C., DUARTE, A.P., PATERNIANI, M.E., RIBEIRO, J.L., BIANCHINI, M.T., KANTHACH, R.A., CASTRO, J.L., SILVEIRA,L.C., DENUCCI, S., SABINO JÚNIOR, J. BOLONHESI, D.\& DE SORDI, G. Severidade de doenças no milho "safrinha" no Estado de São Paulo em 1996. Anais, IV Seminário sobre a Cultura do Milho Safrinha, Assis, SP. 1997. pp. 107115.

FOLEGATTI, M.E.G., LOPES, J.R.S., AMORIM, L., SILVA, W.J., SOLFERINO, O.B., SILVA, H.P.\& PEREIRA, O.A.P. Incidência de enfezamento do milho e população do vetor Dalbulus maidis, em diferentes localidades e épocas de plantio, na safra 95/96. Fitopatologia Brasileira 22:347. 1997.

HRUSKA, A.J., GLADSTONE, S.M. \& OBANDO, R. Epidemic roller coaster: maize stunt disease in Nicaragua. American Entomologist 42:248-252. 1996.

HRUSKA, A.J. \& PERALTA, M.G. Maize response to corn leafhopper (Homoptera: Cicadellidae) infestation and achaparramiento disease. Journal of Economic Entomology 90:604-610. 1997.

LEE, I.M., HAMMOND, R.W., DAVIS, R.E. \& GUNDERSEN, D.E. Universal amplification and analysis of pathogen 16S rDNA for classification and identification of mycoplasmalike organism. Phytopathology 83: 834-842. 1993.

MASSOLA, N.S., BEDENDO, I.P., AMORIM, L. \& LOPES, J.R.S. Quantificação de danos causados pelo enfezamento vermelho e enfezamento pálido do milho em condições 
de campo. Fitopatologia Brasileira 24:136-142.1999a.

MASSOLA, N.S., BEDENDO, I.P., AMORIM, L. \& LOPES, J.R.S. Effects of the inoculation time on corn with Spiroplasma kunkelii on yield components. Fitopatologia Brasileira 24:571-573. 1999b.

MOWAT, W.P. \& DAWSON, S. Detection of plant viruses by ELISA using crude sap extracts and unfractioned antisera. Journal of Virological Methods 15:233-247. 1987.

NAULT, L.R. Maize bushy stunt and corn stunt: a comparison of disease symptoms, pathogen host ranges, and vectors. Phytopathology 70:659-662. 1980.

OLIVEIRA, E., WAQUIL, J.M., FERNANDES, F.T., PAIVA, E., RESENDE, R.O. \& KITAJIMA, E.W. Enfezamento pálido e enfezamento vermelho na cultura do milho no Brasil Central. Fitopatologia Brasileira 23:45-47. 1998.

SCOTT, G.E., ROSEKRANZ, E.E. \& NELSON, L.R. Yield losses of corn due to corn stunt disease complex. Agronomy Journal 69:92-94. 1977.

SHURTLEFF, M.C. Compendium of Corn Disease 2nd ed. St. Paul. American Phytopathological Society.1986.

SILVA, H.P. Identificação e controle das doenças de milho. Informativo Coopercitrus 6:18-24. 1991.

WAQUIL, J.M., VIANA, P.A., CRUZ, I. \& SANTOS, J.P. Incidência da cigarrinha do milho Dalbulus maidis (DeLong\&Wolcott) (Heteroptera-Cicadellidae). Resumos, $16^{\circ}$ Congresso Brasileiro de Entomologia, Salvador, BA. 1997. pp.303. 